\title{
TORSION AND OUT-OF-PLANE MOMENT COUPLING IN CURVED BEAMS AND ARCHES
}

\author{
Amr M. Nafie \\ Civil Engineering Department, Azhar University, Cairo, Egypt
}

\begin{abstract}
Although arches and curved beams have very attractive structure behavior in the plane of curvature, the behavior in the out of plane is very critical. This is due to the coupling effect of the torsional, bending and axial straining actions due to the geometry of the arch / curved beam. In this paper, coupling between the torsional moment and out-of-plane moment in arches was studied. A parametric study was conducted to identify the effect of different parameters on the coupling behavior. It was found that the rise of the arch, the support configuration and the rigidity of the supports had a considerable effect on the value of the out-of-plane moment produced due to torsional load. Similar to arches, horizontally curved beams experienced the same coupling effect in the plane perpendicular to the plane of curvature, i.e. in the vertical plane. In order to emphasize the importance of this phenomenon, a practical example comparing a curved beam and a straight beam was presented. Both beams were subjected to uniform torsional moments. It was shown that the design demand on the curved beam increased by more than $250 \%$ compared to the straight beam due to the secondary moment perpendicular to the plane of curvature induced due to the torsional load. This result showed that if the curved beam is subjected to torsional load, simplifying the design by ignoring the curvature could lead to serious failures even in cases where the curvature is not big.
\end{abstract}

Keywords: Arches, Torsion, Out-Of-Plane Moment, Curved Beam

$* * *$

\section{INTRODUCTION}

Arches have been a very popular form of building in historical structures. This is due to the attractive appearance of arches as well as the structural behavior of arches arising from their geometric properties. An arch can be designed so that the bending action is transformed to compression forces on the arch, with no tension. This behavior was very beneficial in the past where most of the buildings were constructed of stone blocks with no or little tension capacity. Even after the use of reinforced concrete in the modern construction industry, arches are still very popular because they considerably decrease the tension demand on the structure allowing the construction of long unsupported spans, which will not be possible in other forms of building. Historically a structure is called an arch if it is curved in the vertical plane. The curvature can be circular, parabolic or have any other mathematical form. The arch can have a curvature in both the vertical and horizontal planes and as long as the vertical curvature is dominant the term arch can be used. However, the term spatial arch will be more accurate to indicate that the curvature is a $3 \mathrm{D}$ curvature. If the curvature is purely in the horizontal plan the term arch is not usually used and the structure will be called a curved structure.

Although arches and curved beams have very attractive structure behavior in the plane of curvature, the behavior in the out of plane is very critical. This is due to the coupling effect of the torsional, bending and axial straining actions due to the geometry of the arch / curved beam. Many studies have been performed on the lateral torsional stability of arches subjected to vertical or radial in plane loads. Guoet. al. [1] experimentally investigated the lateral stability of fixed arches subjected to vertical in-plane loads. Both symmetric and un-symmetric loads were studied. Dou et. al. [2] studied the same experimental configuration but with inplane pinned supports and out of plane fixed supports. A numerical analysis was also proposed and validated using the experimental results. Pi et. al. [3] studied analytically the lateral torsional buckling of arches having end supports with in-plane rotational restraint and subjected to in-plane radial loading. The effect of the rotational stiffness of the restraint on the buckling of the arch was illustrated. Several studies were conducted to evaluate the buckling loads of arches subjected to different end conditions, different crosssections and different materials. However, most of the studies considered in-plane vertical or radial loading. Research by Guoet. al. [4], Sakimoto et.al. [5] Go et. al.[6] are examples of these studies. The equilibrium and kinematic equations of planar arches have been studied by many researchers e.g. Pi et. al.[7] and Dyme et. al. [8]. The behavior of $3 \mathrm{D}$ arches was studied by SarmientoComesíaset. al. [9] and Wen et. al. [10], among others. Curved beams have also been studied to investigate their behavior and evaluate the ultimate capacity under different conditions and end restraints. Most of the studies considered vertical loadings and used doubly symmetrical sections. Research by Shanmugamet. al. [11], Chamorro-Varilla [12] and Richard Liew [13] are examples of such research.

Most of the previous research conducted on arches or curved beams studied the effect of the vertical or radial loading on the capacity and stability of the arch. The coupling of bending and torsional moment and the effect of normal force on both actions was studied in the context of stability analysis where geometrical imperfections can initiate a non- 
linear out-of-plane mode of failure. It is also a well-known fact in the design of horizontally curved beams that vertical forces on the beam will cause torsional actions that must be checked during the design due to the location of the vertical forces with respect to the axis joining the supports of the beam. Similar to the horizontally curved beams, vertical arches will experience torsion when subjected to horizontal forces perpendicular to the plane of the arch.

In contrast to the effect of the vertical forces discussed above, the effect of torsional moment on the behavior of curved beams and arches has not been discussed in the literature. In this study, the behavior of vertical arches and horizontally curved beams subjected to distributed torsional moment will be presented. Different parameters affecting this behavior will be studied and a practical example will be discussed.

\section{EFFECT OF TORSION ON ARCHES}

Assume a vertical arch subjected to a torsional moment $\mathrm{M}_{\mathrm{t}}$ at a point in the span of the arch as shown in Fig. 1. Because the torsional moment is parallel to the axis of the arch, it will have two components $\mathrm{M}_{\mathrm{t}} \operatorname{Cos} \Theta$ rotating about the horizontal axis and $\mathrm{M}_{\mathrm{t}} \operatorname{Sin} \Theta$ rotating about the vertical axis. Because the angle $\Theta$ is variable along the arch, the horizontal and vertical components of the moment will also vary. The reactions at supports $A$ and $B$ will also have two components $\mathrm{M}_{\mathrm{AX}}$ and $\mathrm{M}_{\mathrm{AY}}$ which are the components of the moment in the vertical and horizontal directions. The reactions can also be transformed into two components $M_{A T}$ in the direction of the support axis causing torsion and $\mathrm{M}_{\mathrm{AP}}$ perpendicular to the support axis causing out of plane moment. Therefore the torsional moment on the arch will cause two straining actions: torsional moment and out-of plane moment.

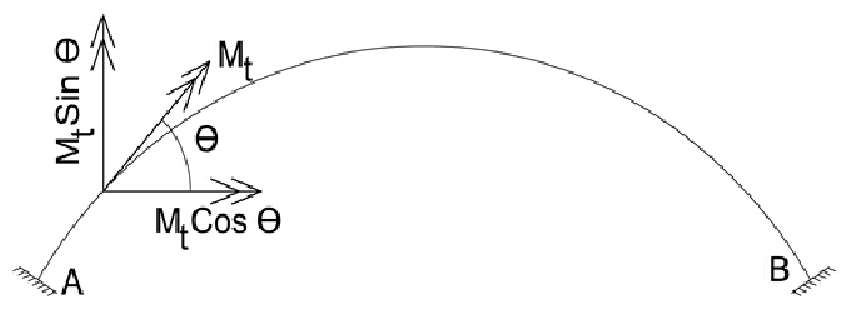

Fig -1: Effect of Torsional Moment on Arches

Fig. 2 shows the torsional moment diagram and out of plane bending moment diagram for a circular arch with span $6 \mathrm{~m}$ and mid-point height of $1 \mathrm{~m}$. The arch is loaded with a distributed torsional moment of $1 \mathrm{mt} / \mathrm{m}$. No other load or moment is applied on the arch. The arch was fully restrained at the left and right end .The arch was divided into a series of straight beams to form the geometric shape of the arch. In order to increase the accuracy of the solution the arch was divided into 100 sub-beams. The arch was analysed using the finite element program SAP2000[14]. As shown in the figure, the torsional moment was approximately $0.4 \mathrm{mt}$ at the left support, the moment decreased gradually reaching zero at the center of the arch, then the moment reversed direction and started to increase reaching a value of $0.4 \mathrm{mt}$ at the right support. In contrast the out-of-plane bending moment was nearly constant with a value of about $4.5 \mathrm{mt}$. An important observation in this analysis is that although the load was pure torsional moment, the produced out-of-plane moment in the arch was about ten times higher than the produced torsional moment.

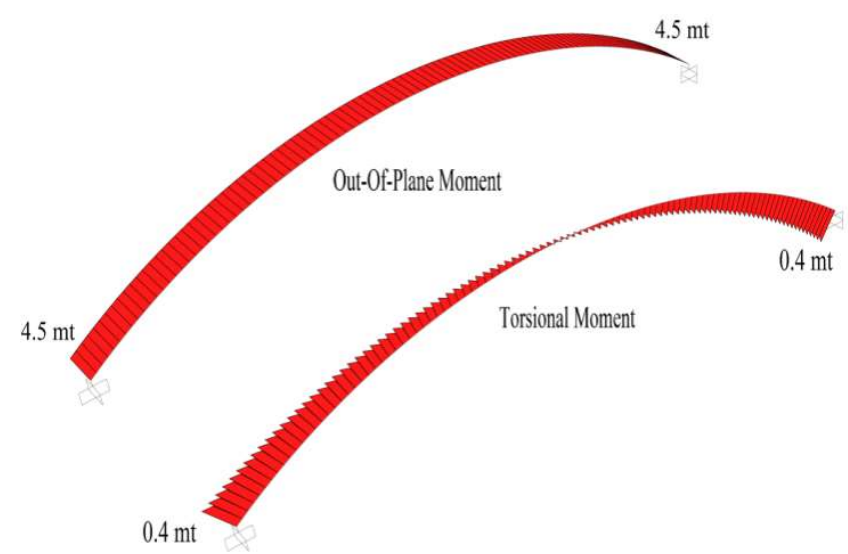

Fig -2: Torsional and Out-of-Plane Moment of an Arch Loaded by a Distributed Torsional Moment

\section{PARAMETERS AFFECTING THE OUT-OF- PLANE MOMENT}

Many factors may affect the values of the out-of-plane and torsional moments, such as the geometry of the arch, the arrangement of the supports and the rigidity of the supports. These factors are studied next.

\subsection{Height of the Arch Vertex}

Height of the vertex (the rise of the arch) is the elevation of the midpoint of the arch with respect to its supports. For the purpose of studying the effect of the vertex height, a circular arch of span $6 \mathrm{~m}$ was used with both ends restrained from translation and rotation. The arch was subjected to a uniform torsional moment of $1 \mathrm{mt} / \mathrm{m}$. Fig. 3 shows the maximum value of the torsional and out-of-plane moments for different vertex heights, $h$. When $h$ is zero, i.e. in the case of a straight beam, the maximum torsional moment on the arch was $3 \mathrm{mt}$, while the out-of plane moment was zero. As the value of $\mathrm{h}$ increased, the torsional moment started to decrease and an out-of-plane moment started to develop in the arch. The out-of plane moment increased with the increase of $\mathrm{h}$ reaching a maximum value of about $6.5 \mathrm{mt}$ at a value of $h$ of about $0.35 \mathrm{~m}$ corresponding to a semi-central angle, $\Theta$, of $13.3^{\circ}$. The corresponding torsional moment at this geometric configuration was $1.55 \mathrm{mt}$. As $\mathrm{h}$ increased further both the torsional moment and the out-of plane moment decreased reaching a limit value at $\mathrm{h}=3 \mathrm{~m}$ with a corresponding $\Theta$ of $90^{\circ}$. The torsional moment at this configuration was zero, while the out-of-plane moment was $3 \mathrm{mt}$. 


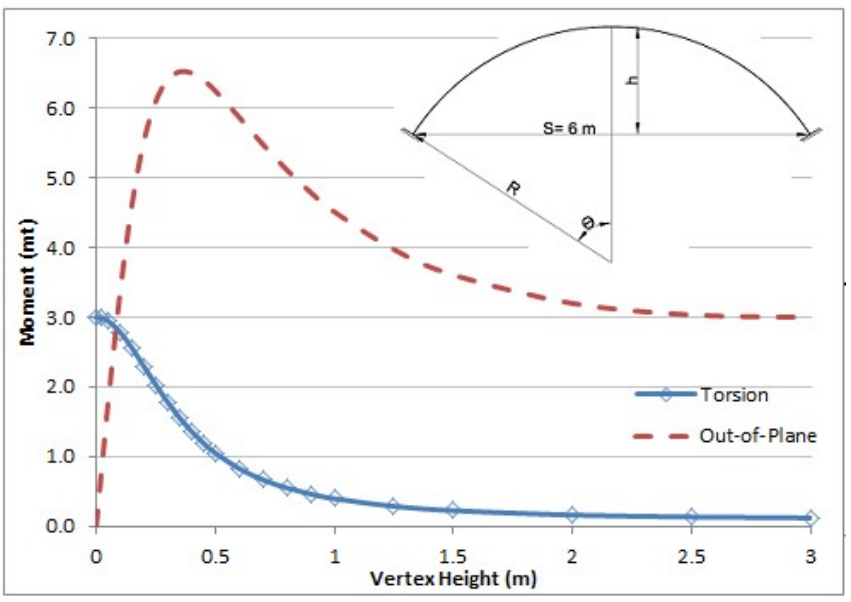

Fig -3: Effect of Vertex Height on Torsional and Out-ofplane Moment

\subsection{Supports Configuration}

Fig. 4 shows the torsional and out-of plane moment on the arch with different support configurations. The arch has $6 \mathrm{~m}$ span with a vertex height of $0.35 \mathrm{~m}$. The two ends of the arch were totally restrained from translation or rotation. The intermediate supports only restrained the out-of plane translation. It is observed from the figure that the variation in the support configuration did not considerably affect the torsional moment where the difference in the torsional moment did not exceed $6 \%$. However, the out-of plane moment was affected by the support configuration. By restraining the out-of-plane movement at the mid-point of the arch, the out-of-plane moment increased from $6.5 \mathrm{mt}$ to $9.9 \mathrm{mt}$, an increase of about $52 \%$. It is also worth mentioning that the resulting out-of-plane moment in this support configuration reached about $60 \%$ higher than the total torsional moment applied on the $\operatorname{arch}(1 \mathrm{mt} / \mathrm{m} \times 6.05 \mathrm{~m}$ $=6.05 \mathrm{mt}$ ).

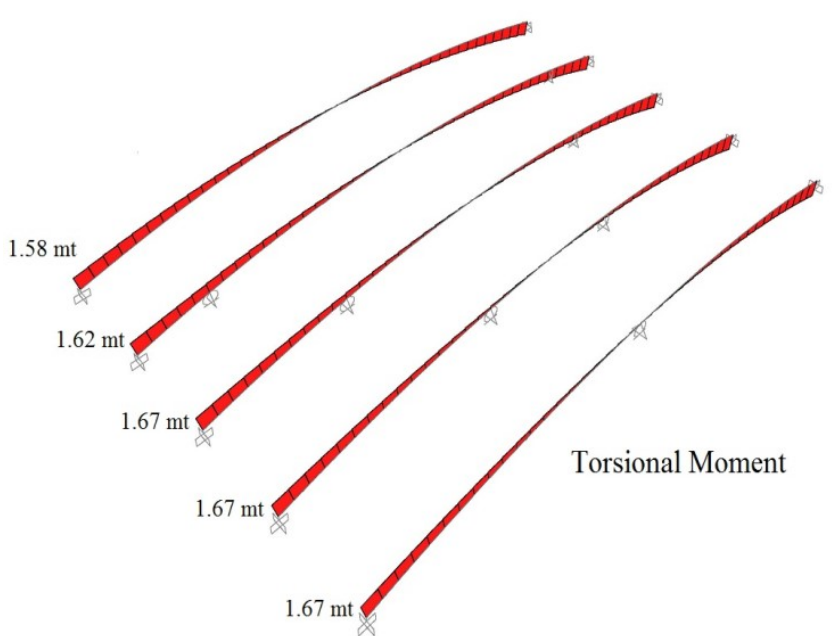

Fig-4a: Effect of Supports Arrangement on Torsional Moment

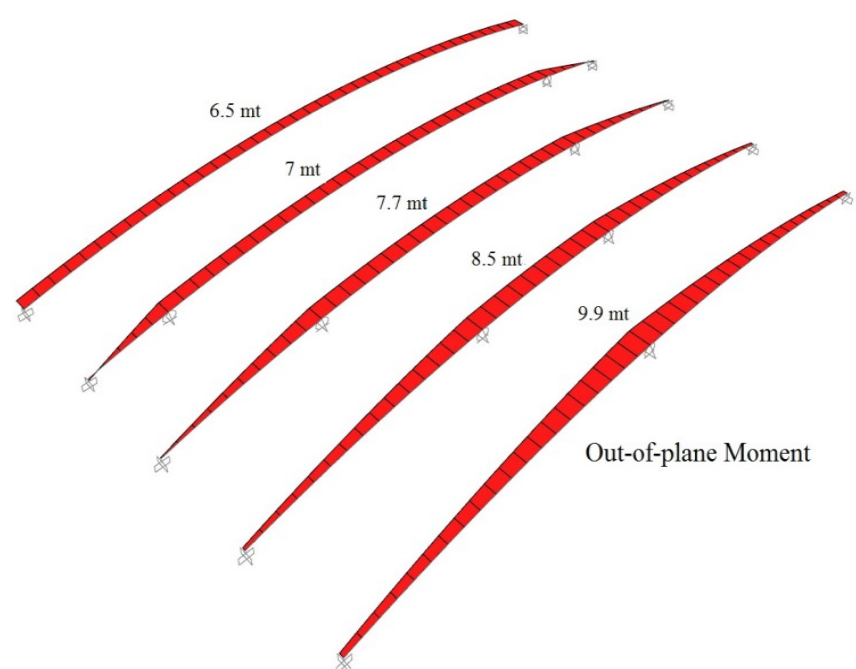

Fig-4b: Effect of Supports Arrangement on Out-of-plane Moment

\subsection{Supports Rigidity}

In order to evaluate the effect of the support rigidity on the out-of-plane moment induced due to torsional load applied on the arch, the arch in Fig. 5 was utilized. The arch had a span of $6 \mathrm{~m}$ and a vertex height, $\mathrm{h}$, of $0.35 \mathrm{~m}$. The two ends of the arch were restrained using a hinged support and a rotational spring which restrains the torsional rotation. The vertex of the arch (point $\mathrm{C}$ ) was restrained using a roller support which restrained the movement in the vertical and out-of-plane directions. Similar to the arch ends, a torsional spring restrained the torsional rotation at point $\mathrm{C}$. The value of the rotational stiffness, $\mathrm{K}$, of the torsional springs was varied to evaluate the effect of the torsional rigidity of the supports on the out-of-plane moments. Fig. 6 illustrates the effect of the rotational stiffness of the torsional springs on the out-of-plane and torsional moment. The figure shows that the out-of-plane moment increased as the torsional stiffness decreased reaching a value of $25.6 \mathrm{mt}$ as the torsional stiffness decreased to $0.1 \mathrm{rad} / \mathrm{sec}$. As the torsional stiffness approached complete rigidity, the out-of-plane moment converged to a value of $3.8 \mathrm{mt}$. This shows the sensitivity of the out-of-plane motion to the torsional stiffness of the supports where the ratio between the maximum and minimum values of the moment was more than 6. The figure also illustrates that the effect of the torsional stiffness on the torsional moment was much less.

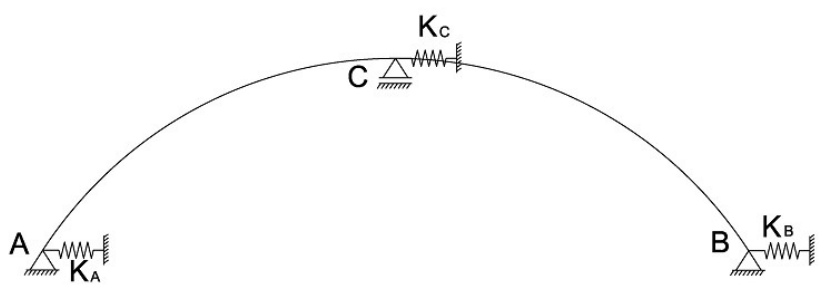

Fig-5: Arch with Hinged Supports and Torsional Springs 


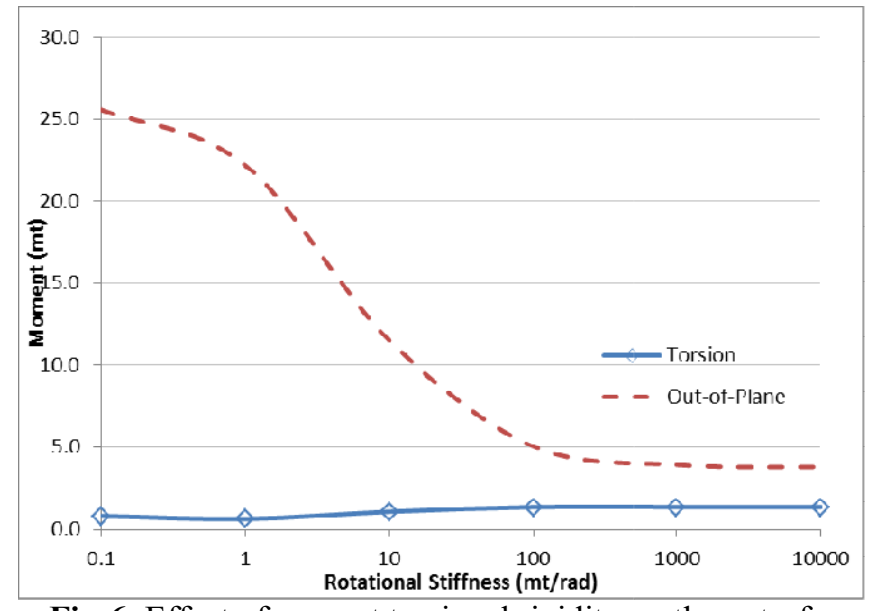

Fig-6: Effect of support torsional rigidity on the out-ofplane moment

\section{A PRACTICAL EXAMPLE}

A practical example which illustrates the coupling between torsional and out-of-plane moments in curved beams is shown in Fig. 7. The figure shows two signboards, $12 \mathrm{~m}$ long and $2 \mathrm{~m}$ high, one board is straight and the other is slightly curved in the horizontal direction with a radius of 26 $\mathrm{m}$. The signboard is supported on a steel frame $3 \mathrm{~m}$ high as shown in the figure. The beam and the external columns are formed of HE140A, while the internal column is made of HE220A. The main load acting on the steel frame is the wind load which will cause bending in the horizontal plane and torsion about the axis of the beam. In this example, the wind load is assumed $0.15 \mathrm{t} / \mathrm{m} 2$, the calculated torsion on the beam will be $0.32 \mathrm{mt} / \mathrm{m}$ and the weight of the signboard is assumed $0.1 \mathrm{t} / \mathrm{m}$.

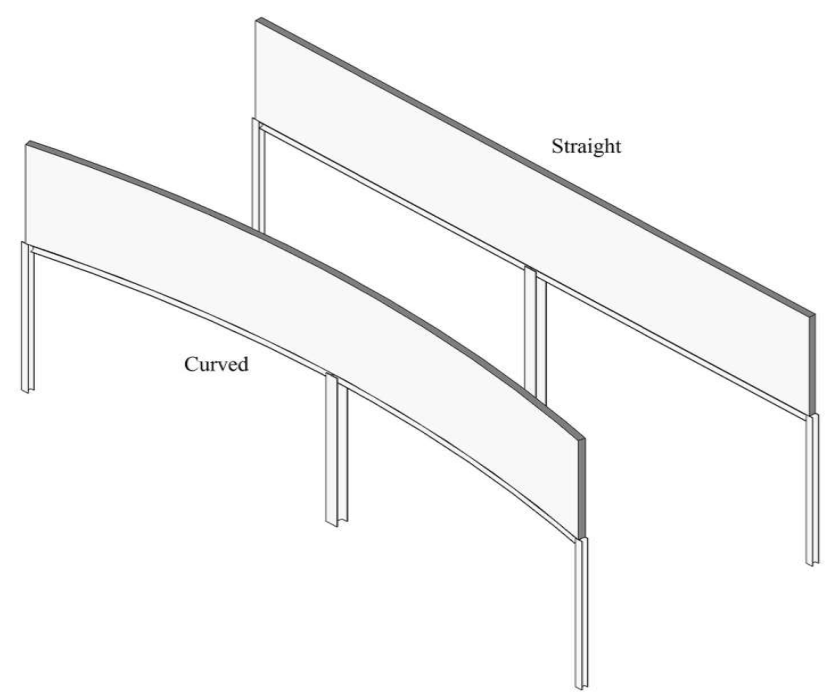

Fig-7: Comparison between a Curved and Straight Signboard

The bending moment in the vertical and horizontal planes due to wind loads (distributed horizontal load and torsion) is shown in Fig. 8. The wind loads caused moments in the horizontal plane which is the plane of the load, in both the straight and the curved beam. The maximum horizontal bending moment in the straight beam was $1.3 \mathrm{mt}$ compared to $1.05 \mathrm{mt}$ for the curved beam. In the vertical plane the wind load didn't cause any moment in the straight beam but induced a considerable moment in the curved beam. The maximum bending moment in the vertical plane in the curved beam due to wind load reached a value of 5.7 mtwhich is more than 5 times the moment induced in the plane of loading. This moment which is perpendicular to the plane of the curve was caused by the torsional moment on the beam, similar to the out-of-plane moment induced in the arch subjected to uniform torsional load as presented earlier.

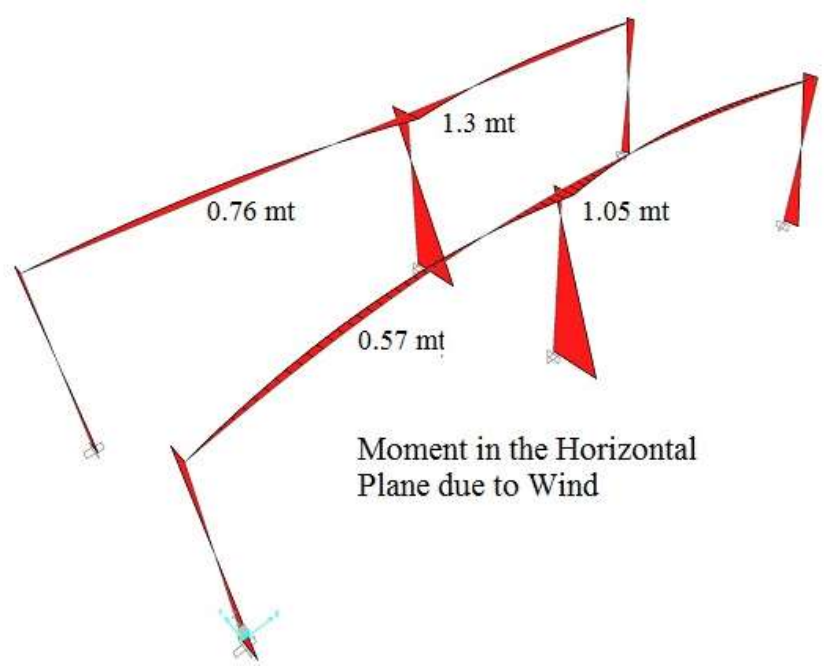

Fig-8a: Moment in the Horizontal Plane Due to Wind Load

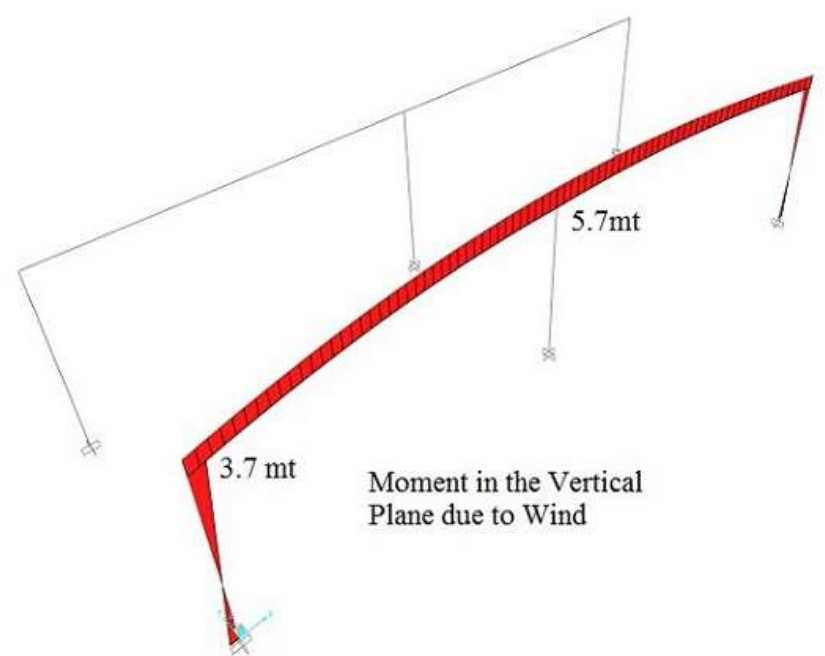

Fig-8b: Moment in the Vertical Plane Due to Wind Load

It is worth mentioning here that the value of the secondary bending moment induced in the circular beam due to torsion is quite large as compared to the main bending in the plane of loading and the resulting torsion in the beam. This can be shown in Fig. 9 where the maximum moments due to wind load and gravity loads on both the curved and straight beam are compared. For the curved beam, the maximum torsion moment was $0.46 \mathrm{mt}$, the maximum primary moment in the vertical plane due to gravity loads was $0.52 \mathrm{mt}$ and the maximum moment in the horizontal plane due to wind was 
$0.46 \mathrm{mt}$. This is compared to maximum value of $5.7 \mathrm{mt}$ for the secondary moment induced due to torsion caused by wind. This secondary moment due to torsion is not produced in the straight beam.

A design check on the beams showed that the demand/capacity ratio for the straight beam was about 0.75 compared to a value of 2.0 for the curved beam. This shows that the secondary moment produced due to curvature of the beam increased the design actions on the beam by more than $250 \%$, and can cause serious failure if this condition is ignored (i.e. if the torsional moment is ignored or the curved beam is approximated as a straight beam to simplify the design).

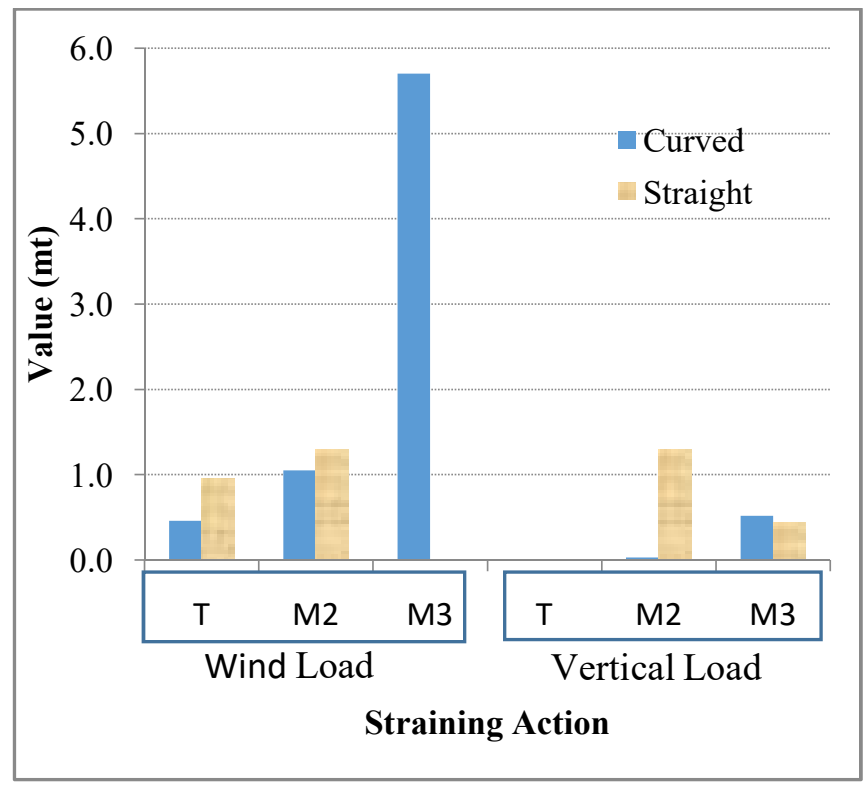

Fig-9: Comparison between the Maximum Moments in the Curved and Straight Beams

\section{CONCLUSIONS}

Coupling between the torsional moment and out-of-plane moment in arches has been studied. A parametric study was conducted to identify the effect of different parameters on the coupling behaviour. It was found that the rise of the arch (height of the vertex) had a major effect on the value of the out-of-plane moment produced. As the rise of the arch increased the value of the out-of-plane moment increased up to a certain limit beyond which the out-of plane moment started to decrease reaching a limiting value as the central angle reached $180^{\circ}$. The support configuration and the rigidity of the supports were also shown to have a considerable effect on the value of the out-of-plane moment. By decreasing the torsional rigidity of the supports the value of the out-of plane moment was increased by more than 6 times compared to that obtained when the supports were rigid. Similar to arches, horizontally curved beams experienced the same coupling effect in the plane perpendicular to the plane of curvature, i.e. in the vertical plane. In order to emphasize the importance of this phenomenon, a practical example comparing a curved beam and a straight beam was presented. Both beams were subjected to uniform torsional moments. It was shown that the design demand on the curved beam increased by more than $250 \%$ compared to the straight beam due to the secondary moment perpendicular to the plane of curvature induced due to the torsional load. This result showed that if the curved beam is subjected to torsional load, simplifying the design by ignoring the curvature could lead to serious failures even in cases where the curvature is not big.

\section{REFERENCES}

[1] Guo Y., Zhao,Pi, Y., Bradford, M. and Dou, C., "An experimental study on out-of-plane inelastic buckling strength of fixed steel arches." Engineering Structures, 98, 118-127, 2015.

[2] Dou, C., Guo Y., Zhao, S. and Pi Y., "Experimental Investigation into Flexural-Torsional Ultimate Resistance of Steel Circular Arches." Journal of Structural Engineering, vol. 141 issue 10, ASCE, 16021609, 2015.

[3] Pi, Y. and Bradford, M. "Lateral-Torsional Buckling Analysis of Arches Having In-Plane Rotational End Restraints under Uniform Radial Loading." Journal of Structural Engineering, vol. 139 issue 11, ASCE, 2013.

[4] Guo, Y., Zhao, S., Dou, C., and Pi, Y., "Out-of-Plane Elastic Buckling of Circular Arches with Elastic End Restraints." Journal of Structural Engineering, vol. 140 issue 10, ASCE, 2014.

[5] Sakimoto, T. and Komatsu, S., 'Ultimate Strength Formula for Steel Arches.' Journal of Structural Engineering, vol. 109 issue 3, ASCE,613-627, 1983.

[6] Go, J., Choi, Y., \& Fang, Z. "Numerical analysis of a circular arch buckling under the symmetric pressure.",Mathematical Problems in Engineering, Vol. 2006 April, 2006.

[7] Pi, Y. and Bradford, M., "In-Plane Analyses of Elastic Three-Pinned Steel Arches." Journal of Structural Engineering, vol. 140 issue 2, ASCE, 2014.

[8] Dym, C. and Williams, H. "Stress and Displacement Estimates for Arches."Journal of Structural Engineering, vol. 137 issue 1, ASCE, 2011.

[9] Sarmiento-Comesías, M., Ruiz-Teran, A., and Aparicio, A.."Structural Behavior of Inferior-Deck Spatial Arch Bridges with Imposed Curvature.", Journal of Bridge Engineering, Vol. 17, ASCE, 2012.

[10] Wen, R. and Suhendro, B.,"Nonlinear Curved-Beam Element for Arch Structures." Journal of Structural Engineering, vol. 117 issue 11, ASCE, 1991.

[11] Shanmugam, N., Thevendran, V., Liew, J., and Tan, L., "Experimental Study on Steel Beams Curved in Plan." Journal of Structural Engineering, vol. 121 issue 2, ASCE, 1995.

[12] Chamorro-Varilla, E. and Aristizabal-Ochoa, J. "Analysis of a Horizontally Curved Long-Span Beam on Two Nonlinear Elastic Supports." Journal of Bridge Engineering, Vol. 21(5), ASCE, 2016.

[13] Richard Liew, J., Thevendran, V., Shanmugam, N., \& Tan, L., "Behaviour and design of horizontally curved steel beams.", Journal of Constructional Steel Research, Vol. 32(1), 37-67, 1995.

[14] Computers and Structures Inc.: "SAP2000 Structural Analysis Program", Computers and Structures Inc., U.S.A. 


\section{BIOGRAPHIES}

Dr Amr Nafie is working as an associate professor in the civil engineering department, Azhar University, Cairo, Egypt. His main research interests are finite element analysis, dynamic analysis, structures strengthening, and structural modeling. He has several published papers in national and international magazines. 